06

\title{
Исследование неоднородности электрохимического электрода со смешанной проводимостью
}

\author{
() А.А. Нечитайлов, Н.В. Глебова, А.А. Томасов, А.О. Краснова, Н.К. Зеленина \\ Физико-технический институт им. А.Ф. Иофрфе РАН, \\ 194021 Санкт-Петербург, Россия \\ e-mail: Aan.shuv@mail.ioffe.ru
}

Поступило в Редакцию 20 мая 2018 г.

В окончательной редакции 22 декабря 2018 г.

Принято к публикации 22 декабря 2018 г.

Методами вольт-амперных характеристик, спектроскопии электрохимического импеданса и моделирования годографа импеданса проведено исследование in situ ионного сопротивления мембранно-электродных блоков кислородно-водородного топливного элемента с электродами, содержащими наночастицы платины на углеродной саже, углеродные нановолокна и протонпроводящий полимер Nafion в широком диапазоне составов ((10-80) mass.\%). Найдены условия, позволяющие корректно определять ионное сопротивление электрода на основе анализа линейной аппроксимации высокочастотной области годографа импеданса. Показано, что возникновение неоднородностей и аномальное увеличение ионного сопротивления при возрастании содержания Nafion в электроде связаны с уменьшением объемной доли центров генерации воды (частиц электрохимически активной платины), приводящим к неполному увлажнению Nafion.

DOI: $10.21883 / J T F .2019 .06 .47637 .203-18$

\section{Введение}

Транспортные свойства электрохимических систем являются одним из важных факторов, определяющих их эффективность [1]. Зарядовый транспорт в электродах твердополимерных топливных элементов и электролизеров, содержащих протонпроводящий полимер типа Nafion и металло-углеродный компонент $(\mathrm{Pt} / \mathrm{C})$, обычно лимитирован транспортом протонов, поскольку ионная проводимость Nafion (удельное сопротивление влажного материала $\left.10^{1} \Omega \cdot \mathrm{cm}\right)$ на несколько порядков меньше электронной проводимости углеродной сажи [2]. Nafion является не единственным компонентом электрода, и увеличение его доли влечет уменьшение пористости и площади доступной поверхности платины [3], одной из задач при разработке электрода является оптимизация его компонентного состава и, в частности, содержания Nafion, с тем, чтобы была обеспечена хорошая газопроницаемость (массовый транспорт) при относительно небольшом ионном сопротивлении.

В наших более ранних исследованиях была обнаружена необычная зависимость ионного сопротивления электрода от содержания ((10-80) mass.\%) Nafion с минимумом в диапазоне (15-20) vol.\% Nafion (около 40 mass.\%). При увеличении содержания Nafion выше 20 vol.\% ионное сопротивление увеличивалось. Мы это связывали предположительно с особенностями водного транспорта в функционирующем электроде и появлением плохо увлажненных областей Nafion, и соответственно неоднородностей по ионному сопротивлению, в электродах с малой объемной долей центров генерации воды (электрохимически активная платина).
Целью настоящей работы является выяснение причин и механизмов появления этих зависимостей ионного сопротивления электродов в широком диапазоне содержания Nafion.

\section{1. Рабочая модель}

В мембранно-электродном блоке (МЭБ), состоящем из последовательных слоев: катода, мембраны, анода в условиях генерации и протекания электрического тока имеют место следующие массовые потоки:

1 - молекулярный кислород диффундирует из прикатодного объема в пористый катод;

2 - молекулярный водород диффундирует из прианодного объема в пористый анод, где на поверхности платинированной углеродной сажи расщепляется на гидратированные протоны и электроны;

3 - гидратированные протоны перемещаются через влажную мембрану (Nafion) на катод.

На катоде на поверхности платины гидратированные протоны соединяются с кислородом, образуя воду, которая диффундирует в двух направлениях: в сторону прикатодного пространства и через мембрану в сторону анода.

Учитывая, что каждый протон с анода уносит некоторое количество молекул воды на катод (водный электроосмотический коэффициент переноса протона $K$ изменяется от 0.4 до 1.6 при влагосодержании Nafion от 6 до 22 молекул воды на сульфогруппу соответственно по данным [4]), можно сделать вывод о том, что анод осушается. Обратный же поток воды на анод возникает за счет воды, образующейся в результате стан- 
дартной экзотермической электрохимической реакции $4 \mathrm{H}^{+} \cdot \mathrm{KH}_{2} \mathrm{O}+\mathrm{O}_{2}+4 e^{-}=(K+2) \mathrm{H}_{2} \mathrm{O}+\mathrm{Q}$.

Температура в зоне реакции всегда выше, чем на поверхности электрода и в приэлектродном пространстве, что способствует выносу воды продуваемыми газами (кислородом и водородом) даже в случае, когда их относительная влажность близка к 100\%. В связи с этим возникает и градиент концентрации воды в направлении прикатодного пространства.

Распределение воды в системе зависит от многих факторов, наиболее значимыми из которых являются, наряду с пористостью и гидрофильностью электродов, поляризация и плотность тока [5-7].

При относительно небольших поляризациях, в области BAX с преобладанием активационных и резистивных, и незначительным влиянием диффузионных потерь можно считать, что концентрация кислорода практически одинаковая по толщине катода (несколько уменьшается к мембране) и, следовательно, можно считать, что выделение воды также близко к равномерному по толщине катода. Таким образом, концентрационный профиль воды в катоде будет выглядеть как кривая с максимумом в толще электрода с уменьшением концентрации к границам с прикатодным пространством и мембраной. При больших поляризациях в соответствие с правилами электрохимической кинетики [8] зона электрохимической реакции и соответственно область выделения воды вытесняется на поверхность электрода.

Также необходимо учитывать зависимость количества переносимых с анода на катод молекул воды от плотности тока и изменение вклада конвективного переноса молекул воды при различной пористости электрода, зависящей от содержания Nafion.

В соответствии с этим даже при условии однородности исходного состава электродов в них могут возникать неоднородности свойств в процессе генерации электрического тока. Наиболее значимым явлением в этом случае можно считать неоднородность ионного сопротивления, связанную с неоднородностями влажности и температуры. Влажность влияет на сопротивление в большей степени, так как ионное сопротивление Nafion сильнее зависит от этого параметра $[9,10]$.

При относительно большой доле центров генерации электрического тока (и соответственно воды), т.е. при большой доле электрохимически активной платины в материале электрода количество унесенной с продуваемыми газами воды меньше количества выделяемой воды в результате электрохимической реакции, имеет место положительный баланс по воде [11]. В обратном случае, когда воды уносится больше, чем генерируется, имеет место отрицательный баланс по воде, и влажность МЭБ поддерживается за счет влажности продуваемых газов и находится на более низком уровне.

Важным обстоятельством является то, что влажность Nafion, находящегося в равновесии, например, с кислородом со $100 \%$ относительной влажностью, не достигает ее предельной возможной величины (около 22 молекул
$\mathrm{H}_{2} \mathrm{O}$ на одну группу $-\mathrm{SO}_{3} \mathrm{H}$ ) и соответственно его ионное сопротивление примерно в 3-5 раз выше сопротивления полностью гидратированного Nafion $[12,13]$.

Таким образом, при небольшом количестве центров генерации воды появляется возможность того, что неоднородность влажности электрода вызывает неоднородность ионного сопротивления.

Заметим, что величина электрохимической емкости в общем случае носит пороговую зависимость от влажности, так как образование двойного электрического слоя происходит на границе электронный проводник/раствор электролита. Если весь электрод увлажнен, то неравномерность влажности не оказывает сильного влияния на емкость. По этой причине в рабочей модели не проведено подробное рассмотрение вклада неоднородности емкости двойного слоя электрода.

\section{2. Материалы и методы}

\section{Образцы}

Исследовали серию МЭБ-системы Pt/C-УНВ-Nafion различного компонентного состава, площадью электродов $1 \times 1 \mathrm{~cm}$. Компонентный состав меняли таким образом, чтобы получить образцы с различной долей платины и Nafion (табл. 1).

Использовали многостенные углеродные нановолокна типа Таунит МД (производства ООО „НаноТехЦентр“, Тамбов [14]), платинированную углеродную сажу с массовым содержанием платины 40\% (коммерческий продукт марки E-TEK) и коммерческий раствор Nafion. Формирование электродов проводили способом, предусматривающим предварительное коагулирование Nafion из его раствора в жидкой фазе с последующим введением в структуру электрода [15].

МЭБ изготовлены путем нанесения однородной дисперсии компонентов непосредственно на протонпроводящую мембрану через маску из нержавеющей стали. Перед нанесением электродного материала мембрану выдерживали в $0.5 \mathrm{M}$ серной кислоте в течение $15 \mathrm{~min}$ при температуре $(70-80)^{\circ} \mathrm{C}$ с последующей пятикратной промывкой водой. Электроды изготавливали путем нанесения дисперсии компонентов в смеси изопропанол-вода на протонпроводящую мембрану типа Nafion (марка МФ4-СК) толщиной $50 \mu \mathrm{m}$. Мембрану термостатировали при $85^{\circ} \mathrm{C}$ на плитке типа IkaC-MAGHP 7 с терморегулятором. Количество нанесенного материала контролировали гравиметрически.

Пористость измеряли исходя из геометрии электрода (толщину электрода измеряли толщиномером) и компонентного состава по известным соотношениям [16].

\section{Проведение измерений}

Использовали двухэлектродный метод. Образцы МЭБ помещали в коммерческую ячейку типа FC-05-02 (ElectroChemInc, контактное сопротивление $<5 \mathrm{~m} \Omega$ ) и 
Таблица 1. Характеристики исследуемых МЭБ

\begin{tabular}{|c|c|c|c|c|c|c|c|c|c|c|c|}
\hline 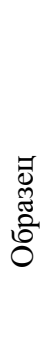 & 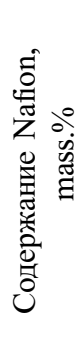 & $\begin{array}{l}\hat{0} \\
0 \\
0 \\
0 \\
0 \\
0 \\
0 \\
0\end{array}$ & 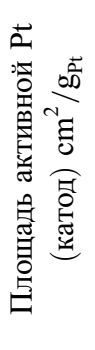 & 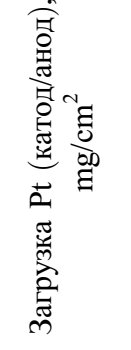 & 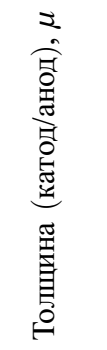 & 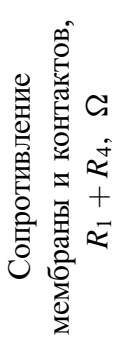 & 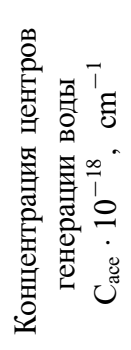 & 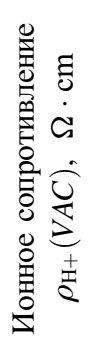 & 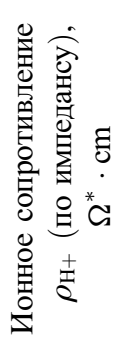 & 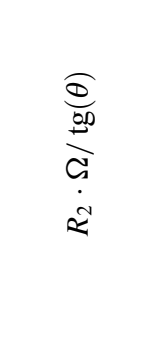 & $\begin{array}{l}\text { G } \\
\text { ผ } \\
\stackrel{N}{\text { L }}\end{array}$ \\
\hline 1 & 2 & 3 & 4 & 5 & 6 & 7 & 8 & 9 & 10 & 11 & 12 \\
\hline 72 & 10 & 77 & 14 & $0.04 / 0.02$ & $3.3 / 1.8$ & 0.20 & 4.1 & 7450 & 3950 & $0.77 / 1.35$ & 1.31 \\
\hline 73 & 25 & 77 & 57 & $0.1 / 0.07$ & $14 / 7.7$ & 0.11 & 12 & 175 & 98 & $0.135 / 1.04$ & 0.15 \\
\hline 67 & 40 & 68 & 100 & $0.1 / 0.08$ & $14 / 12$ & 0.11 & 20 & 110 & 220 & $0.265 / 1.06$ & 0.3 \\
\hline 68 & 60 & 52 & 82 & $0.12 / 0.11$ & $14 / 14$ & 0.14 & 38 & 280 & 140 & $0.21 / 0.72$ & 0.19 \\
\hline 74 & 80 & 12 & 20 & $0.12 / 0.09$ & $15 / 14$ & 0.79 & 3.9 & 1010 & 670 & $\begin{array}{l}(6.1-3.5) / \\
(0.05-0.1)\end{array}$ & 1.01 \\
\hline
\end{tabular}

активировали путем циклического изменения разности потенциалов от напряжения разомкнутой цепи до $\sim 0 \mathrm{~V}$ со скоростью $10 \mathrm{mV} / \mathrm{s}$ в системе $\mathrm{O}_{2} / \mathrm{H}_{2}$, в следующих условиях: относительная влажность газов > 90\%, атмосферное давление, температура близка к $23^{\circ} \mathrm{C}$. Поток газов составлял $\sim 20 \mathrm{ml} / \mathrm{min}$. Периодически меняли направление подачи газов. При этом регистрировали ВАХ. Активацию проводили до стабилизации ВАХ [17].

\section{Измерение BAX}

ВАХ регистрировали с использованием потенциостата типа Р-150 (производство ООО „Элинс“, Черноголовка); в среде $\mathrm{O}_{2} / \mathrm{H}_{2}$ при атмосферном давлении и температуре $23^{\circ} \mathrm{C}$. Относительная влажность газов $>90 \%$, ионное сопротивление вычисляли по наклону линейного участка ВАХ с учетом величины сопротивления переноса заряда, как в [16].

\section{Измерение площади электрохимически активной поверхности платины}

Площадь электрохимически активной поверхности платины измеряли по стандартной методике по электрохимической десорбции водорода (ЦВА) $[8,18]$.

\section{Регистрация спектра электрохимического импеданса}

При получении годографа импеданса с целью анализа его высокочастотной области существуют два способа его регистрации: используют пары газов - водород/азот (азот на исследуемый электрод) и водород/кислород (кислород на исследуемый электрод) [19-21]. В первом случае в значительной степени исключаются паразитные реакции, но во втором случае условия измерения годографа ближе к рабочим условиям МЭБ.
В нашем случае сразу после окончания активации образца регистрировали его годограф импеданса в тех же условиях (газы, влажность, давление, температура), что и проводили активацию. Годограф регистрировали прибором Z500X + AX500PL при напряжении, близком к напряжению разомкнутой цепи (поляризация $(0-100) \mathrm{mV})$ при амплитуде переменного напряжения $8 \mathrm{mV}$, сопротивлении переноса заряда $R_{3}>80 \Omega$, в интервале частот $(500 \mathrm{kHz}-0.1 \mathrm{~Hz})$.

\section{Моделирование спектров электрохимического импеданса}

Исследованию и определению ионного сопротивления электродов МЭБ методом спектроскопии электрохимического импеданса посвящено много публикаций, например [19-22]. В работах [19-21] показана возможность использования методов, основанных на анализе высокочастотной части годографа для измерения ионного сопротивления электродов. В [22] проведено математическое моделирование различных случаев неоднородностей катода, но без объяснения возможной природы этих неоднородностей.

При проведении моделирования мы применили общепринятую эквивалентную схему МЭБ (рис. 1) [20,21] и одномерную модель, разбивая электрод на 9-10 равных по толщине частей, и использовали программу ZView 2.3 [23].

Проводили два типа моделирования: 1 - построение чисто модельных спектров, задавая величины элементов эквивалентной электрической схемы (рис. 2, 3; табл 2, 3); 2 - подгонка модельных спектров к экспериментальным выбором величины элементов эквивалентной электрической схемы до наилучшего совпадения спектров. Далее определяли ионное сопротивление электрода, используя линейную аппроксимацию высокочастотной части годо- 


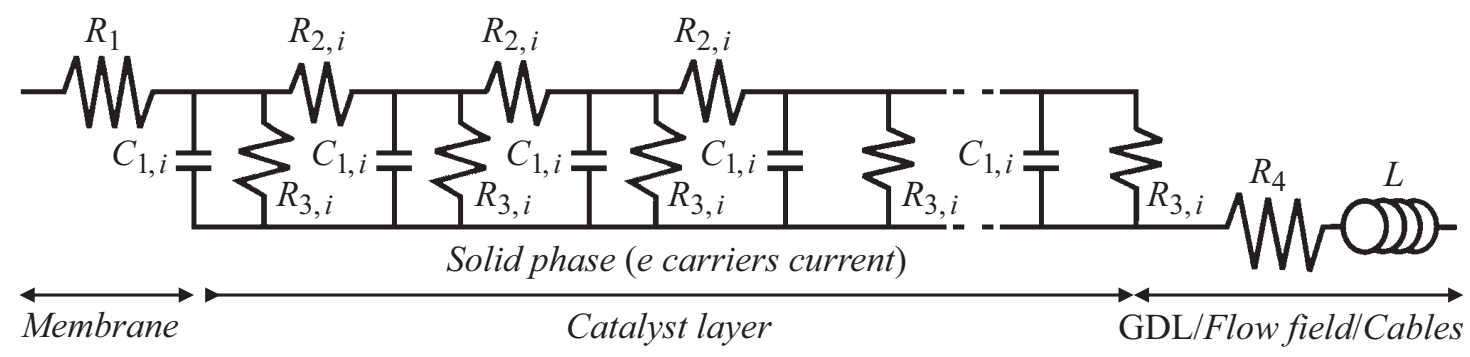

Рис. 1. Эквивалентная электрическая схема, используемая при моделировании годографа электрохимического импеданса: $R_{1}$ - ионное сопротивление мембраны; $R_{2 i}-$ ионное сопротивление $i$-слоя электрода; $R_{3 i}-$ сопротивления переноса заряда $i$-слоя электрода; $C_{1 i}-$ емкость двойного $i$-слоя электрода; $R_{4}-$ сопротивление контактов и проводов; $L-$ паразитная индуктивность ячейки и проводов.
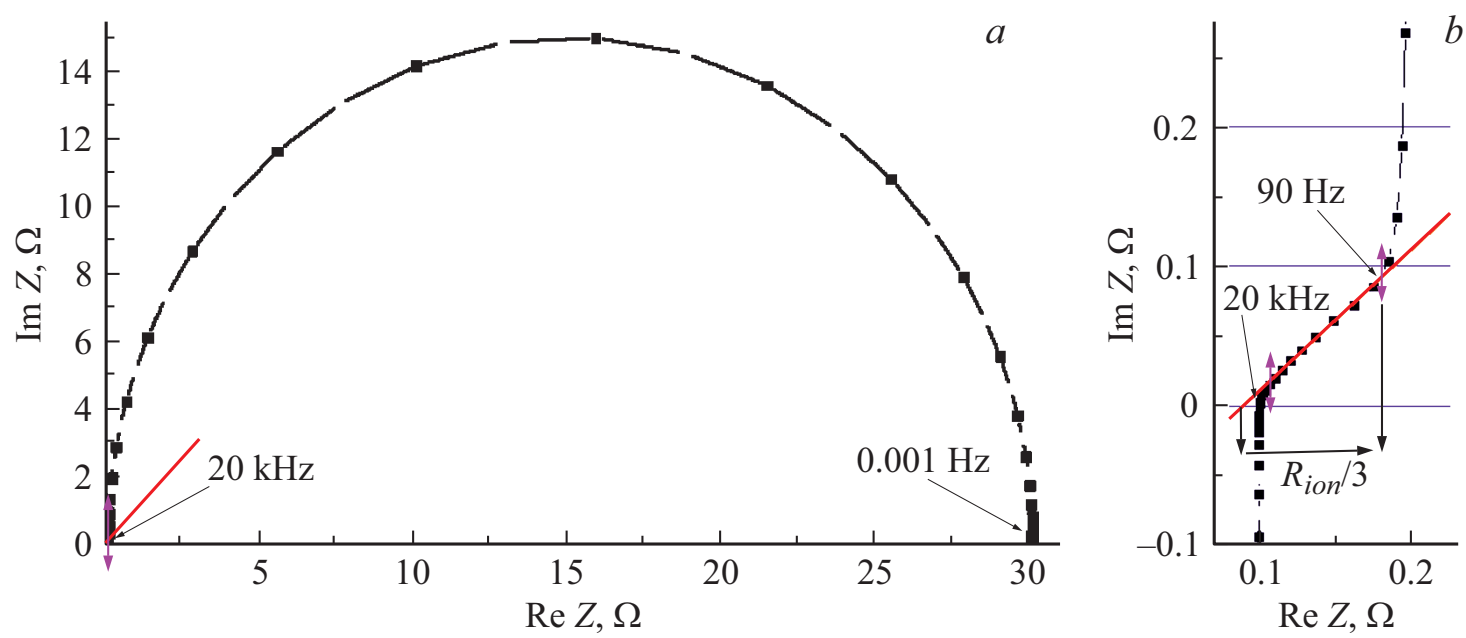

Рис. 2. Модельный годограф импеданса для однородного электрода: $a-$ полный годограф; $b-$ высокочастотная область годографа (-口-); линейная аппроксимация $(-) ; R_{3} / R_{2}=100$.

Таблица 2. Величины ионного сопротивления электрода для однородных образцов, полученные по результатам моделирования при различных значениях сопротивления переноса заряда

\begin{tabular}{c|c|c|c|c|c|c|c}
\hline № & $R_{3}, \Omega$ & $R_{2}, \Omega$ & $R_{2}^{*}, \Omega$ & $\operatorname{tg}(\theta)$ & $\left(R_{1}+R_{4}\right), \Omega$ & $C_{1}, \mathrm{~F}$ & $L, \mathrm{H}$ \\
\hline 1 & 0.15 & & 0.393 & 0.607 & & & \\
2 & 0.3 & & 0.45 & 0.815 & & & \\
3 & 1.0 & & 0.298 & 0.938 & & & \\
4 & 3.0 & 0.3 & 0.277 & 0.989 & 0.1 & 0.0275 & $3 \cdot 10^{-8}$ \\
5 & 10 & & 0.275 & 1.007 & & & \\
6 & 30 & & 0.275 & 1.01 & & & \\
7 & 300 & & 0.274 & 1.01 & & &
\end{tabular}

графа $\left(R_{2}^{*}\right)[19,20](1)$, а также суммируя $R_{2 \text { I }}$ по всем слоям $\left(R_{2 \Sigma}\right)$ :

$$
R_{2}^{*}=A \cdot \Delta \mathrm{Re},
$$

где $\Delta \mathrm{Re}$ - величина, равная разнице между проекцией на ось $\operatorname{Re}$ точки перегиба высокочастотной части годографа и точкой пересечения линейной экстраполяции высокочастотной части годографа с осью $\operatorname{Re}($ рис. $2, b)$; $A \approx 3[19,20]$.

Первоначально целью моделирования было определение условий для корректного использования выражения (1) в случае однородных электродов при разных соотношениях элементов эквивалентной схемы (рис. 1), а также выяснение влияния неоднородности ионного сопротивления $\left(R_{2 \mathrm{I}}\right)$ на форму годографа и корректность применения выражения (1) при определении ионного сопротивления (сравнение значений $R_{2}^{*}$ и $R_{2 \Sigma}$ ).

Далее проводили подгонку модельного годографа к экспериментальному. В качестве подгоночных параметров использовали ионное сопротивление, сопротивление электрохимической реакции (переноса заряда, $R_{3}$ ) и емкость. Сопротивления контактов, протонпроводящей мембраны и электрохимической реакции определяли из экспериментальных данных. Сумма сопротивления контактов $(<5 \mathrm{~m} \Omega)$ и мембраны, определенная по высокочастотной отсечке годографа $\left(R_{\mathrm{Hf}}\right)$, для исследованных образцов находилась в интервале $0.1-0.8 \Omega$ (табл. 1)).Сопротивление переноса заряда в экспери- 
Таблица 3. Величины ионного сопротивления электрода в случае его неоднородности, полученные на основе результатов моделирования годографа импеданса методом послойного суммирования и линейной аппроксимации линейного участка

\begin{tabular}{|c|c|c|c|c|c|c|c|c|c|c|}
\hline \multirow[b]{2}{*}{ № слоя } & \multicolumn{2}{|c|}{ Model N1 } & \multicolumn{2}{|c|}{ Model N2 } & \multicolumn{2}{|c|}{ Model N3 } & \multicolumn{2}{|c|}{ Model N4 } & \multicolumn{2}{|c|}{ Model N5 } \\
\hline & $\begin{array}{c}R_{2}, \\
\Omega\end{array}$ & $\begin{array}{c}R_{2}^{*} \\
\Omega / \operatorname{tg}(\theta)\end{array}$ & $\begin{array}{c}R_{2 i}, \\
\Omega\end{array}$ & $\begin{array}{c}R_{2}^{*} \\
\Omega / \operatorname{tg}(\theta)\end{array}$ & $\begin{array}{c}R_{2 i}, \\
\Omega\end{array}$ & $\begin{array}{c}R_{2}^{*} \\
\Omega / \operatorname{tg}(\theta)\end{array}$ & $\begin{array}{c}R_{2 i}, \\
\Omega\end{array}$ & $\begin{array}{c}R_{2}^{*} \\
\Omega / \operatorname{tg}(\theta)\end{array}$ & $\begin{array}{c}R_{2 i}, \\
\Omega\end{array}$ & $\begin{array}{c}R_{2}^{*} \\
\Omega / \operatorname{tg}(\theta)\end{array}$ \\
\hline 1 & 0.03 & & 0.003 & & 0.3 & & 0.03 & & 0.3 & \\
\hline 2 & 0.03 & & 0.003 & & 0.03 & & 0.06 & & 0.27 & \\
\hline 3 & 0.03 & & 0.03 & & 0.03 & & 0.09 & & 0.24 & \\
\hline 4 & 0.03 & & 0.03 & & 0.03 & & 0.12 & & 0.21 & \\
\hline 5 & 0.03 & $0275 / 101$ & 0.03 & $0146 / 151$ & 0.03 & $(2.1-3.1) /$ & 0.15 & $0503 / 164$ & 0.18 & \\
\hline 6 & 0.03 & $0.210 / 1.01$ & 0.03 & $0.146 / 1.51$ & 0.03 & $(0.3 / 0.2)$ & 0.18 & $0.593 / 1.64$ & 0.15 & $2.31 / 0.81$ \\
\hline 7 & 0.03 & & 0.03 & & 0.03 & & 0.21 & & 0.12 & \\
\hline 8 & 0.03 & & 0.03 & & 0.03 & & 0.24 & & 0.09 & \\
\hline 9 & 0.03 & & 0.03 & & 0.03 & & 0.27 & & 0.06 & \\
\hline 10 & 0.03 & & 0.03 & & 0.03 & & 0.3 & & 0.03 & \\
\hline $1-10$ & 0.3 & & 0.246 & & 0.57 & & 1.65 & & 1.65 & \\
\hline
\end{tabular}

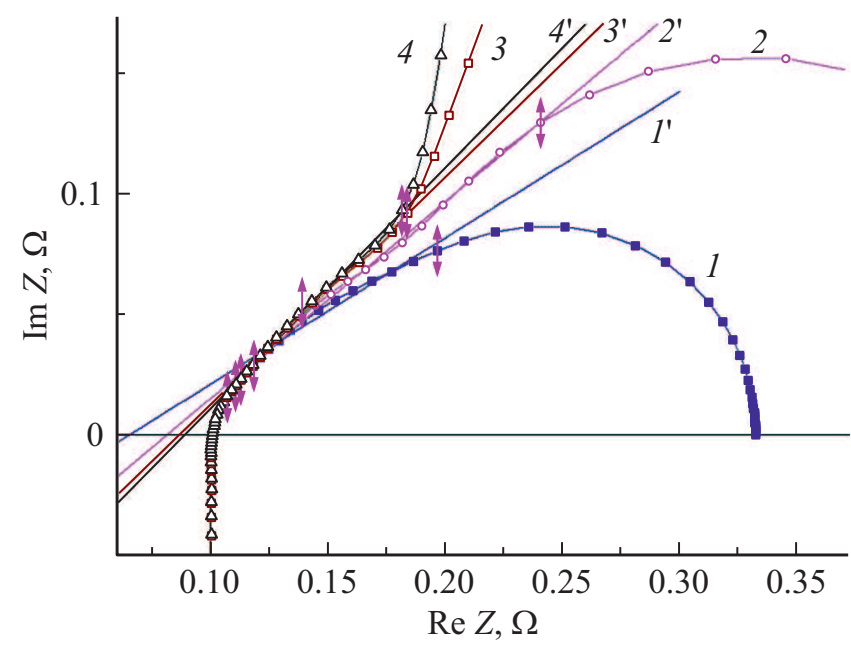

Рис. 3. Модельные годографы импеданса и линейные аппроксимации к их высокочастотным областям однородного электрода при разных соотношениях между сопротивлением переноса заряда и ионным сопротивлением электрода: 1 $(-\boldsymbol{-}-) R_{3} / R_{2}=0.5 ; 2-(-\circ-) R_{3} / R_{2}=1.0 ; 3-(-\square-)$ $R_{3} / R_{2}=3.3 ; 4-(-\triangle-) R_{3} / R_{2}=10.0 ;\left(1^{1}-4^{1}\right)-$ аппроксимация к линейной области $(-) ;(\uparrow-\uparrow)$ диапазон линейной аппроксимации; $R_{2}=0.3 \Omega$.

ментальных условиях было существенно выше ионного сопротивления и составляло $R_{3}>80 \Omega$.

\section{Определение концентрации центров генерации воды}

Концентрацию центров генерации воды $-C_{\text {act }}\left(\mathrm{cm}^{-1}\right)$ вычисляли как количество электрохимически активных атомов платины катода (метод ЦВА), приведенных к единичному объему всего МЭБ, по соотношению

$$
C_{\mathrm{act}}=\frac{210 \cdot 10^{-6} \cdot A \cdot S_{\mathrm{Pt}}}{F \cdot \delta}
$$

где $210 \cdot 10^{-6} \mathrm{C} / \mathrm{cm}^{2}$ - заряд, протекающий через электрохимическую систему при десорбции водорода с $1 \mathrm{~cm}^{2}$ поверхности платины; $A-$ число Авогадро; $S_{\mathrm{Pt}}\left(\mathrm{cm}^{2}\right)-$ площадь электрохимически активной поверхности платины в катоде; $F$ - постоянная Фарадея; $\delta(\mathrm{cm})-$ толщина активной квадратной области МЭБ размерами $1 \times 1 \mathrm{~cm}$, включающая сумму толщин катода, мембраны и анода.

\section{3. Результаты и обсуждение}

\section{Результаты моделирования спектров электрохимического импеданса}

На рис. 2 приведен годограф импеданса однородного электрода при соотношении сопротивления переноса заряда $\left(R_{3}\right)$ к ионному сопротивлению электрода $\left(R_{2}\right)$, равному 100. Видно, что полный годограф (рис. 2, $a$ ) имеет классическую форму, а тангенс угла наклона $(\operatorname{tg}(\theta))$ линейной экстраполяции высокочастотной области годографа (рис. 2, b) близок единице (1.01). Значения ионного сопротивления электрода, полученные по выражению (1) $\left(R_{2}^{*}\right)$, полученные путем суммирования по всем слоям $\left(R_{2 \Sigma}\right)$ и заданные при моделировании $\left(R_{2}\right)$, практически совпадают (табл. 2, № 6). Некоторое различие величин $\left(R_{2}=0.3, R_{2 \Sigma}=0.3, R_{2}^{*}=0.275\right)$ связано с тем, что коэффициент $(A)$, полученный в результате упрощения уравнений, описывающих модель, не точно равен $3[19,20]$.

На рис. 3 представлены модельные спектры электрохимического импеданса для однородных электродов при разных соотношения $R_{3} / R_{2}$. Результаты моделирования 


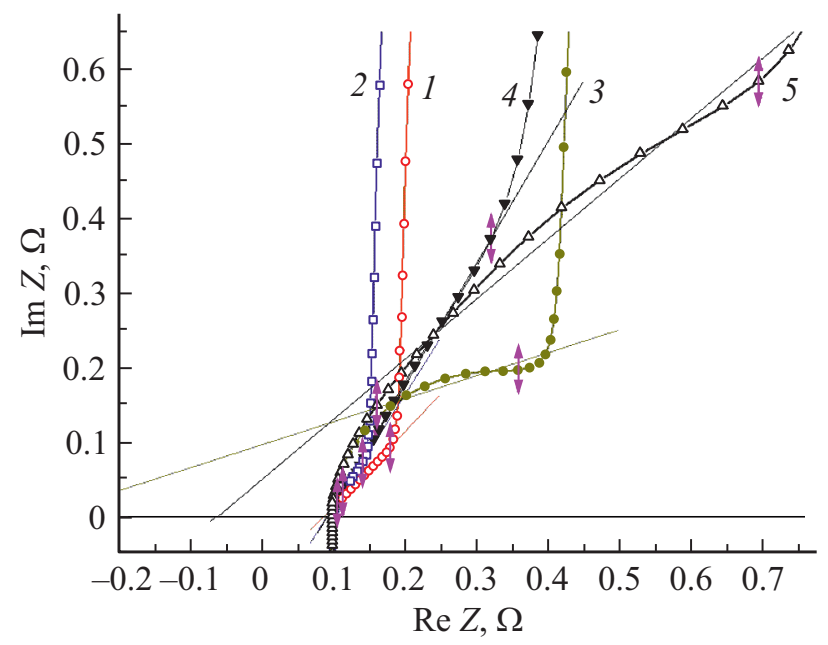

Рис. 4. Модельные годографы высокочастотной области импеданса для МЭБ, имеющие неоднородность только по профилю ионного сопротивления рабочего электрода: 1 - Model N 1(-०-); 2 - Model N 2 (- $\square-) ; 3-$ Model N 3 (-•-); 4 - Model N4 (- - -); 5 - Model N $5(-\triangle-)$; аппроксимация к линейной области - соответствующая сплошная линия $(-)$; $(\uparrow-\uparrow)$ - диапазон линейной аппроксимации; $R_{3} / R_{2}>20$.

сведены в табл. 2. Из приведенных данных (табл. 2) следует, что для корректного определения $R_{2}$ по соотношению (1), даже в случае однородных электродов необходимо выполнение условия $-R_{3} / R_{2}>(3-5)$ и значение $\operatorname{tg}(\theta)$ в пределах $(1.0 \pm 0.2)$. В противном случае необходима подгонка модельного годографа к экспериментальному и суммирование ионного сопротивления по слоям. Обратим внимание, что в случае при значениях $R_{3} / R_{2}<1$ форма полного годографа значительно отличается от классической.

На рис. 4 приведены высокочастотные области годографов импеданса МЭБ для электродов, имеющих неоднородности только по ионному сопротивлению. Данные модели и результаты приведены в табл. 3. В качестве моделей были выбраны наиболее вероятные, исходя из физической модели (см. выше) виды профиля неоднородностей ионного сопротивления при недостаточном увлажнении электрода.

Данные, приведенные на рис. 4 и в табл. 3, показывают сильное влияние неоднородностей ионного сопротивления на форму высокочастотной области годографа и на $\operatorname{tg}(\theta)$ линейной экстраполяции этого участка. Обратим внимание, что форма высокочастотной области годографа импеданса и значения $\operatorname{tg}(\theta)$ кардинально отличаются для случаев нахождения неоднородности около мембраны (рис. 4, кривая 2, табл. 3, Model N2) и около газодиффузионного слоя (рис. 4, кривая 3, табл. 3, Model N3). В первом случае $(\operatorname{tg}(\theta)=1.51)$ ионное сопротивление, найденное согласно (1), значительно меньше заданного при моделировании, а во втором $(\operatorname{tg}(\theta)=(0.3 \pm 0.2))$ - больше, и использование соотношения (1) носит условный характер из-за боль- шой неопределенности при нахождении величины $\operatorname{tg}(\theta)$. Аналогичное поведение наблюдается и при линейном изменении ионного сопротивления по слоям (рис. 4, кривые 4,5, табл. 3, Model N4, N5).

Таким образом, необходимым условием использования выражения (1) для корректного определения ионного сопротивления является значение $\operatorname{tg}(\theta)$, близкое к единице. В противном случае (при сильном отличии $\operatorname{tg}(\theta)$ от 1) желательно проводить подгонку экспериментальных спектров и послойное суммирование ионного сопротивления.

\section{Результаты эксперимента}

В табл. 1 сведены характеристики исследованных образцов. На рис. 5 приведены высокочастотные области годографов электрохимического импеданса и подгоночные зависимости для двух характерных образцов с различным содержанием Nafion. Из рисунка видно, что для образца с содержанием Nafion, близком к обычно используемому (40\%, рис. 5, N67), годограф имеет форму, близкую к классической для однородного электрода, т. е. в высокочастотной области присутствует линейный участок $(\operatorname{tg}(\theta)=1.06)$ с углом наклона $\approx 45^{\circ}$. Годограф образца с высоким содержанием Nafion $(80 \%$, рис. 5 , N74) имеет уже искаженную форму $(\operatorname{tg}(\theta)=(0.3-02))$, близкую к форме модельного годографа (рис. 4, кривая 3, табл. 3, Model N3), и свидетельствует о неоднородности характеристик электрода и некорректности применения выражения (1). В остальных случаях (табл. 1, колонки 11,12$)$ при приближении значения $\operatorname{tg}(\theta)$ к единице происходит сближение величин $R_{2}^{*}$ и $R_{2 \Sigma}$.

На рис. 6 приведены профили ионного сопротивления катода исследуемых МЭБ, полученные подгонкой к высокочастотной области экспериментальных годографов импеданса согласно описанной выше модели.

Анализируя данные, приведенные на рис. 6 можно сделать следующие выводы. Ионное сопротивление катода для образцов N67, N68, N73 с относительно большой концентрацией активных центров

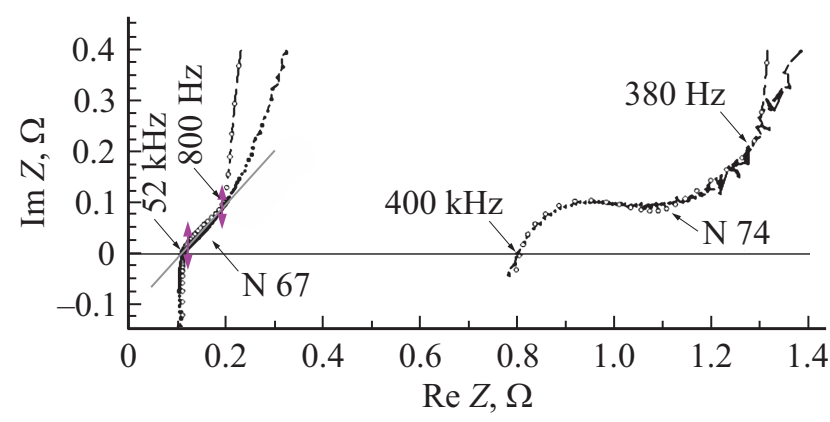

Рис. 5. Экспериментальные и модельные высокочастотные области годографов импеданса: МЭБ № 67 (Nafion 40\%), (ם - экспериментальные, -о- - модельные, - - линейная аппроксимация), $\operatorname{tg}(\theta)=1.06$ (46 ${ }^{\circ}$ ); № 74 (Nafion 80\%) (ム экспериментальные; (-о- - модельные). 


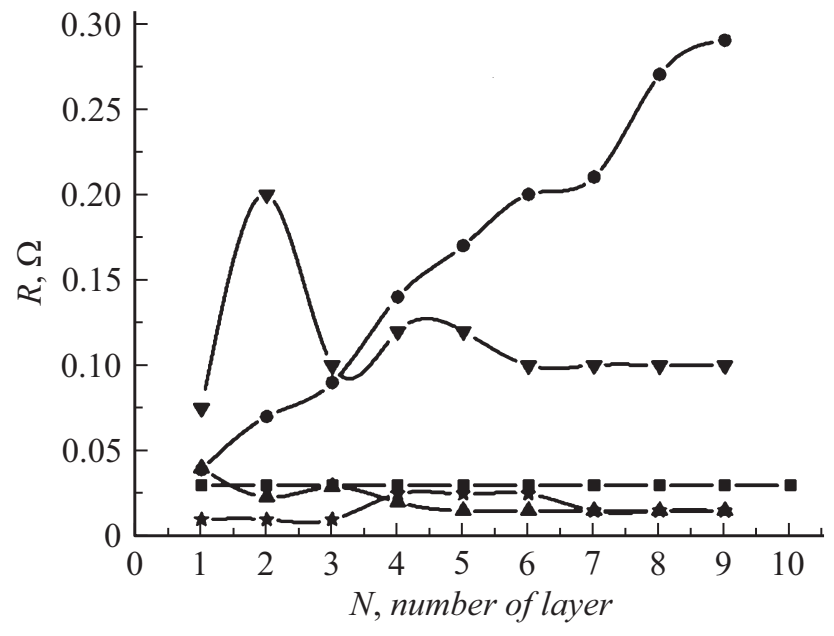

Рис. 6. Профили ионного сопротивления электрода, полученные на основании результатов экспериментальных и модельных годографов импеданса для МЭБ с разным содержанием Nafion: № $72-10 \%(-\bullet-)$; № $73-25 \%$ (- -$)$;

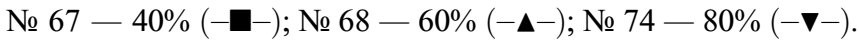

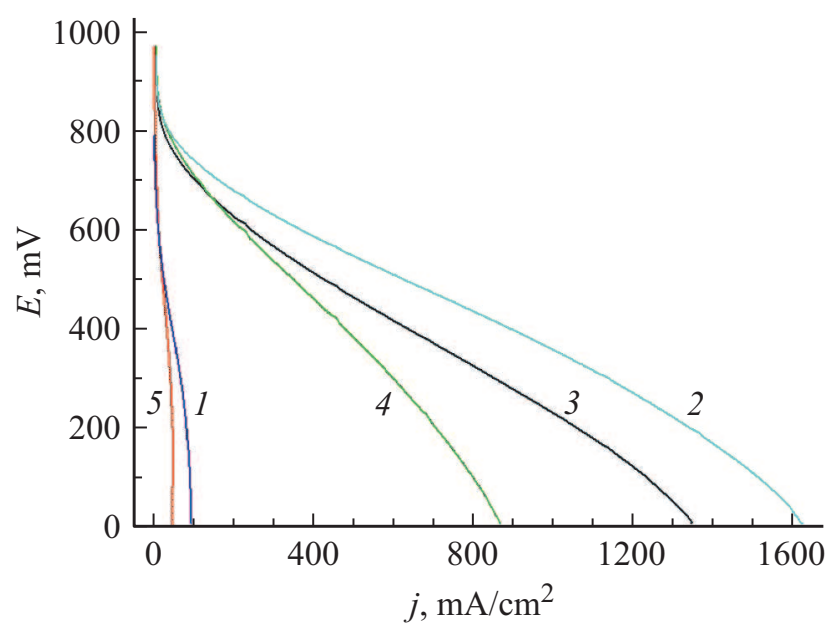

Рис. 7. ВАХ МЭБ с различным содержанием Nafion в электродах: $1-10 \%$ (№ 2); $2-25 \%$ (№ 73); $3-40 \%$ (№ 67); $4-60 \%$ (№ 68); $5-80 \%$ (№ 74); влажные газы (кислород/водород), скорость поляризации $2 \mathrm{mV} / \mathrm{s}$.

генерации воды (табл. 1, колонка 8), находящейся в интервале $(12-38) \cdot 10^{18} \mathrm{~cm}^{-1}$, имеет относительно невысокие значения и распределение его по толщине электрода относительно равномерное. Для образцов N72, N74 с малой концентрацией активных центров $\left((3.9-4.1) \cdot 10^{18} \mathrm{~cm}^{-1}\right)$ ионное сопротивление значительно выше и сильно неоднородно по толщине электрода. Причем для более пористого образца с меньшей толщиной электрода (N72) сопротивление сильно возрастает к границе с прикатодным пространством, тогда как для образца с малой пористостью (N74), ионное сопротивление увеличено у границы с мембраной. Это свидетельствует о том, что в первом случае происходит осушение внешнего слоя электрода, которое можно объяснить увеличенным вкладом конвекции в переносе воды с потоком кислорода в прикатодном пространстве.

Отметим, что величина сопротивления, полученная по высокочастотной отсечке годографа $\left(R_{1}+R_{4}\right.$, табл. 1 , колонка 7) коррелирует с местонахождением неоднородностей ионного сопротивления электрода (рис. 6). Учитывая, что $R_{4} \ll R_{1}$, можно утверждать, что эта зависимость связана с сопротивлением мембраны $\left(R_{4}\right)$.

Так, МЭБ N74 имеет увеличенное сопротивление у мембраны, а МЭБ N73, N67 и N68 имеют относительно невысокие значения ионного сопротивления, что также подтверждает полученные профили неоднородностей.

Таким образом, используя подгонку экспериментальных годографов, согласно модели (рис. 1), можно более точно определить величину ионного сопротивления электрода, чем по соотношению (1), и найти его характерный профиль.

На рис. 7 представлены ВАХ исследуемых МЭБ. Используя соотношения, полученные в работе [17], были рассчитаны величины удельного ионного сопротивления образцов (табл. 1, колонка 9).

Из анализа данных (табл. 1, колонка 9,10) видна общая тенденция зависимости ионного сопротивления от содержания Nafion и центров генерации воды $\left(C_{\text {act }}\right)$, и приемлемое совпадение величин удельного ионного сопротивления, полученных на основе анализа ВАХ и моделирования экспериментальных годографов. Расхождения ионного сопротивления (при одинаковой общей тенденции), измеренного двумя разными методами, можно объяснить различием методик и условий измерения (различным состоянием МЭБ), оно требует отдельных исследований.

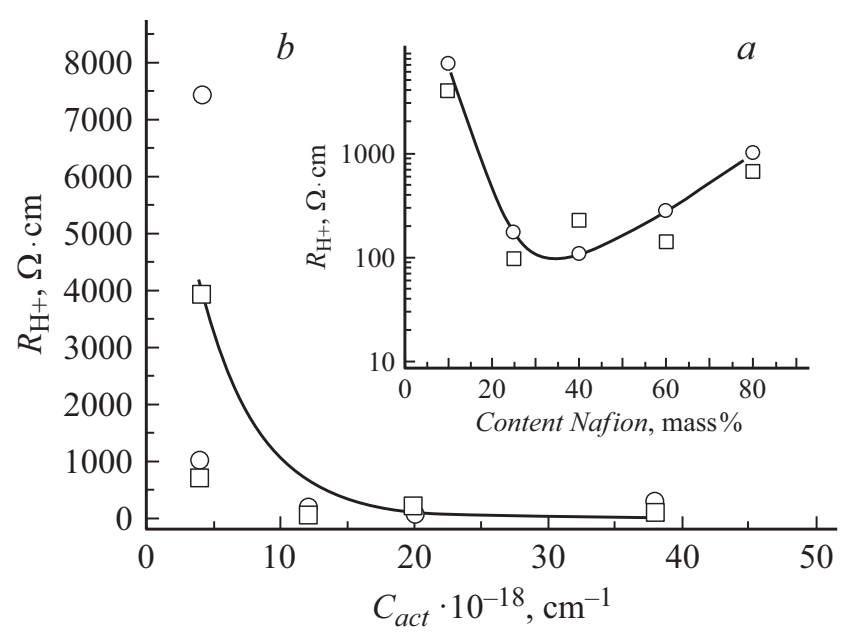

Рис. 8. Зависимости удельного ионного сопротивления электрода: $a-$ от содержания Nafion; $b-$ от концентрации активных центров генерации воды; для величин, рассчитанных на основе анализа данных ВАХ и моделирования годографов импеданса (Imp). о - расчетные ВАХ, $\square-$ моделирование импеданса, - - аппроксимация. 
Кроме того, может иметь место разный механизм переноса протонов. При измерении по ВАХ протоны по большей части переносятся по Nafion, входящему в зону электрохимической реакции (в межфазную область, где происходит генерация воды). Тогда как при регистрации годографа импеданса вклад в ионную проводимость может вносить и Nafion вне этой области.

На рис. 8 приведены зависимости удельного сопротивления электрода, полученные описанными выше методами, от содержания Nafion и центров генерации воды.

Из рис. 8 , а видно, что удельное ионное сопротивление электродов имеет минимум при содержании Nafion в диапазоне $(25-40) \%$. При дальнейшем увеличении содержания Nafion сопротивление увеличивается. На зависимости этого же сопротивления от концентрации активных центров генерации воды (рис. $8, b$ ) видно, что ионное сопротивление начинает резко возрастать, когда концентрация активных центров становится меньше $12 \cdot 10^{18} \mathrm{~cm}^{-1}$. Это соответствует образцу с содержанием Nafion 25\%. Наблюдаемые закономерности свидетельствуют о связи полного ионного сопротивления с концентрацией активных центров генерации воды. Кроме того, данные, приведенные на рис. 6, показывают, что образцы с относительно небольшой концентрацией активных центров генерации воды имеют неоднородное ионное сопротивление по толщине электрода.

\section{Заключение}

Установлено, что корректное определение ионного сопротивления электрода по линейной аппроксимации высокочастотной области годографа импеданса возможно в случае величины тангенса угла наклона этой аппроксимации,близкой к единице $(< \pm 20 \%)$.

Использование аппроксимации модельных спектров к экспериментальным позволяет получить профиль неоднородности ионного сопротивления исследуемых электродов.

Появление неоднородностей в однородном по составу электроде и увеличение его ионного сопротивления связано как с малой долей центров генерации электрического тока и воды, так и с высокой пористостью электродов, приводящими к неоднородному увлажнению Nafion в процессе работы МЭБ.

Области, обедненные водой, с увеличенным ионным сопротивлением в электродах с относительно небольшой пористостью находятся вблизи мембраны. В случае же электродов с относительно большой пористостью и с возрастающим влиянием конвекции на влагообмен, обедненные водой слои с увеличенным ионным сопротивлением находятся на поверхности, граничащей с прикатодным пространством.

Полученные зависимости ионного сопротивления от содержания Nafion и активных центров генерации воды (атомов электрохимически активной платины), имеют важное прикладное значение при разработке электрохимических электродов, особенно при широко распространенном в последнее время проектировании электродов с ультрамалой загрузкой платины, где также необходимо обеспечить оптимальный водный режим функционирования МЭБ, обеспечивающий полное увлажнение Nafion.

\section{Список литературы}

[1] Asmatulu R., Khan A., Adigoppula V.K., Hwang G. // Int. J. Energy Res. 2018. Vol. 42. P. 508-519.

[2] Shetzline J.A., Creager S.E. // J. Electrochem. Society. 2014. Vol. 161. N 14. P. H917-H923.

[3] Okumura M., Noda Z., Matsuda J., Tachikawa Y., Nishihara M., Lyth S.M., Hayashi A., Sasaki K. // J. Electrochem. Society. 2017. Vol. 164. N 9. P. F928-F934.

[4] Xu F., Leclerc S., Stemmelen D., Perrin J.-K., Retournard A., Canet D. // J. Membrane Sci. 2017. Vol. 536. P. 116-122.

[5] Fathi H., Raoof A., Mansouri S.H. // J. Power Sources. 2017. Vol. 349. P. 57-67.

[6] Нечитайлов А.А., Глебова Н.В., Кошкина Д.В., Томасов А.А., Зеленина Н.К., Терукова Е.Е. // Письма в ЖТФ. 2013. Т. 39. Вып. 17. С. 17-26. [Nechitailov A.A., Glebova N.V., Koshkina D.V., Zhilina D.V., Tomasov A.A., Zelenina N.K., Terukova E.E. // Tech. Phys. Lett. 2013. Vol. 39. P. 762-766.]

[7] Глебова Н.В., Нечитайлов А.А., Краснова А.О., Томасов А.А., Зеленина Н.К. // ЖПХ. 2015. Т. 88. Вып. 5. C.726-731. [Glebova N.V., Nechitailov A.A., Krasnova A.O., Tomasov A.A., Zelenina N.K. // Russ. J. Appl. Chem. 2015. Vol. 88. P. 769-774.]

[8] Zhang J. // PEM Fuel Cell Electrocatalysts and Catalyst Layers. Vancouver. Springer, 2008. P. 113.

[9] Proton Conductivity of Nafion 117 as Measured by a Four-Electrode AC Impedance Method, http://jes.ecsdl.org/content/143/4/1254

[10] Matos B.R., Goulart C.A., Santiago E.I., Muccillo R., Fonseca F.C. // Appl. Phys. Lett. 2014. Vol. 104. P. 091904.

[11] Нечитайлов А.А., Глебова Н.В., Краснова А.О., Томасов А.А., Зеленина Н.К. // ЖТФ. 2015. Т. 85. Вып. 11. C. 97-103. [Nechitailov A.A., Glebova N.V., Krasnova A.O., Thomasov A.A., Zelenina N.K. // Tech. Phys. 2015. Vol. 60. N 11. P. 1670-1676.]

[12] Liu L., Chen W., Li Y. // J. Membrane Sci. 2016. Vol. 504. P. 1-9.

[13] Saito M., Arimura N., Hayamizu K., Okada T. // J. Phys. Chem. B. 2004. Vol. 108. P. 16064-16070.

[14] URL. http://www.nanotc.ru/index.php/producrions/87-cnmtaunit

[15] Litster S., McLean G. // J. Power Sources. 2004. Vol. 130. P. 61-76.

[16] Глебова Н.В., Краснова А.О., Томасов А.А., Зеленина Н.К., Нечитайлов А.А. // ЖТФ. 2017. Т. 87. Вып. 6. С. 880-883. [Glebova N.V., Krasnova A.O., Tomasov A.A., Zelenina N.K., Nechitailov A.A. // Tech. Phys. 2017. Vol. 62. N 6. P. 895-898.]

[17] Андроников Д.А., Зеленина Н.К., Терукова Е.Е., Томасов А.А. Способ активации мембранно-электродного блока. Патент № 2487442, заявка № 2012107563 от 28.02.2012. [Andronikov D.A., Zelenina N.K., Terukova E.E., Tomasov A.A. RF Patent N 2487442 (2012).] 
[18] Kocha S.S. Handbook of Fuel Cells-Fundamentals, Technology and Applications. / Eds. W. Vielstich, H.A. Gasteiger, A. Lamm. Chichester: John Wiley and Sons, UK, 2003. Vol. 3. 538 p.

[19] Cruz-Manzo S., Chen R., Rama P. // J. Fuel Cell Sci. Technol. 2012. Vol. 9. P. 051002-1-8.

[20] Jiang R., Mittelsteadt C.K., Gittleman C.S. // J. Electrochem. Society. 2009. Vol. 156. N 12. P. B1440-B1446.

[21] Makharia R., Mathias M.F., Bakerb D.R. // J. Electrochem. Society. 2005. Vol. 152. N 5. P. A970-A977.

[22] Gerteisen D. // J. Electrochem. Society. 2015. Vol. 162. N 14. P. F1431-F1438.

[23] Электронный ресурс. Режим доступа: http://www.ameteksi.com/products/software/zview-software 